\title{
THE CONTRIBUTION OF COGNITIVE ANTHROPOLINGUISTICS TO EDUCATIONAL LINGUISTICS
}

\author{
José Manuel Martín MoriLlas \\ University of Granada
}

\begin{abstract}
In this paper it is argued that, despite the welcome psycho-social emphasis in educational linguistic theories witnessed in recent decades, and with it, a rapprochement of the social sciences to the psychological sciences, the relationship between these fields has not gone far enough. The actual challenge is a move towards the unification of the social, psychological and language sciences (anthropology and sociology; cognitive science; and linguistics). A step in this interdisciplinary direction is offered by the discipline called 'cognitive anthropolinguistics', and its central concept of 'cultural cognition'. The paper discusses the implication of this concept for the field of educational linguistics, followed by a brief illustration of a cognitive-cultural application of that concept, namely the concept of 'ethnic stereotype', as part of a socio-cultural guide for a cross-cultural pedagogical grammar.
\end{abstract}

\section{INTRODUCTION}

1.1 The relation of applied linguistics (or, as we prefer to call it, educational linguistics (EdL), a term coined by Bernard Spolsky in the seventies to refer to the theory of language learning and teaching) to other basic or ancillary disciplines has undergone drastic and far-reaching changes throughout time. The scope of the nurturing disciplines and sciences providing foundational theoretical bases for applied/educational linguists has grown increasingly broader and broader with the realization that language learning and language teaching are extremely complex processes whose full understanding, let alone manipulation and implementation, remains somewhat beyond our complete grasp, 
and in need of constant reassessment and reflection. At first, structural linguistics was the sole contributor to the disciplinary basis of EdL (this led to a rather narrow view of applied linguistics, nutshelled in the contrastive analysis hypothesis). Later on, psychology and psycholinguistics as well as pragmatics and the social sciences (sociolinguistics and anthropology) were added to the list of fundamental sciences. Today, the standard view on the nature and scope of EdL, and on its relation to other sciences, maintains a threefold division between: a) the language sciences (theoretical linguistics, descriptive and contrastive linguistics, typolinguistics, and other branches of linguistics); b) the "mind" sciences (cognitive psychology and psycholinguistics); and c) the social sciences (anthropology, sociology and social psychology). This threefold division can be found, for instance, in the organization of the well-known textbook Fundamental Concepts of Language Teaching by the late H.H. Stern (1983). We find in it the following division of its contents: I. Concepts of Language; II. Concepts of Society; III. Concepts of Learning. In his introductory remarks on the contents of the section devoted to concepts of society, entitled "The social sciences and the second language curriculum", Stern comments that,

"the relations between the social sciences and language teaching have developed differently from the relations between language teaching and linguistics [and psychology]. Contacts were established later in the history of language pedagogy, and the interaction has been far less intensive. The development of the relationship has not been one of similar dramatic ups and down. In the fifties and sixties, an anthropological and sociological view of language in connection with culture and society began to influence language teaching theory to a limited extent. Earlier thinking on language and society was directed to historical studies or philosophy. Sociolinguistics as a relative newcomer in the language sciences has only quite recently become involved in pedagogy" (Stern 1983: 246).

Towards the end of the section in the chapter devoted to the critical assessment and historical review of the influence of social disciplines on language teaching theory until the eighties, Stern (1983: 246) asserts, in a succint assessment of the state of the art in the mid-eighties, that "language teaching theory today [has acquired] a sociolinguistic component, [but] still lacks a well-defined socio-cultural emphasis". Partly motivated by this deficiency in language teaching theory, Stern (1983: 256) proposes in that same chapter a metatheoretical model of the relationship of the language teaching operation to the social sciences, intended to provide a more solid socio-anthropological basis for EdL. The model proposed is built around a three-tier architecture of multidisciplinariness, whose contents are developed in six progressive steps of integration and implementation. The three-level arrangement is intended to capture the division between a bottom level of fundamental sciences, a middle level of implications for a theory of educational linguistics (ie., a semi-autonomous component made up of 
the integration of a theory of language, a theory of learning, a theory of context, and a theory of teaching, and a top level of application and implementation). These levels are spelled out as follows (see fig. 1 below):

a) Level I: specification of relevant theories, concepts, universals, etc from anthropology, sociology and sociolinguistics; b) Level II: specification of the socio-cultural component of a pedagogical grammar (in the form of a sociocultural guide to the society and culture of the target language); c) Level III: specification of the elements of the sociocultural/sociolinguistic guide of the target society and culture to be included in the syllabus and the actual teaching methodology. Procedurally, the six stages from theory to application work as follows: drawing on theories and concepts from the fundamental sciences (step 1), which serve as starting points for producing studies on the target society and culture (S2 and C2) (step 2), the applied linguist arrives at a series of ethnographic descriptions of S2 and C2) (step 3), from which s/he may derive a number of implications (or insights) converging into the sociocultural component of the pedagogical grammar, which makes up the core of the Educational Linguistic level of the overall model (step 4). Finally, steps 5 and 6 involve the methodological specifications for the design of the syllabus and for the teaching implementation of socio-cultural information in the classroom.

\begin{tabular}{|c|c|c|}
\hline \multirow{2}{*}{ Level III } & Sociocultural aspect in teaching materials & Step 6 \\
\hline & Sociocultural component of S2 / C2 (syllabus) & Step 5 \\
\hline Level II & $\begin{array}{lr}\text { Learning } & \text { Teaching } \\
\text { Sociocultural Pedagogical Guide } \\
\text { Social Context }\end{array}$ & Step 4 \\
\hline \multirow{3}{*}{ Level I } & Ethnographic Description of S2 and C2 & Step 3 \\
\hline & Research studies on S2 and C2 & Step 2 \\
\hline & $\begin{array}{l}\text { Anthropology/Sociology/Sociolinguistics } \\
\text { (theories-concepts-universals) }\end{array}$ & Step 1 \\
\hline
\end{tabular}

Figure 1. Interaction between the social sciences and EdL (Stern 1983) 
Stern's conception of the relationship of EdL to the social sciences is a widespread one among theoreticians and practioners in the field. Under this conception, and owing to the fact that the goals applied linguists recommend for developing communicative competence are strongly influenced by classical cultural anthropological and ethnographic theories and models, the key concepts on which the edifice of the contribution of the social sciences to EdL is made to rest are those of 'culture' and 'communicative competence'. With regard to the concept of 'culture', it is a widespread belief among educational linguists that, despite the influence of anthropological and ethnographic thought, which has made possible great advances not only in objectives, techniques, topics in cultural teaching, but also in methods of testing cultural knowledge (see, inter alia, Seelye 1984; Kramsch, 1993), the classical concept of ' culture' remains somewhat intuitive and, methodologically, unmanageable. Stern himself, in the abovementioned chapter, points out the following set of problems with regard to the classical concept of culture (1983: 251): a) problems concerning the breadth and scope of the concept: that is, the problem of making the comprehensive anthropological definitions of 'culture' sufficiently relevant and applicable in the context of EdL; b) problems concerning the interaction of language to culture; that is, the problem of understanding the interfaces between linguistic competence and cultural competence; c) problems in the training of teachers as social scientists; that is, the problem of training teachers not only to have access to anthropological documentation but also to become social scientists themselves; d) problems concerning the embedding of the above in the language teaching operation; that is, the problem of transferring all this theoretical information into the classroom, and, consequently, of converting the cultural knowledge imparted into communicative socio-cultural skills. As regards the concept of 'communicative competence' -a term Dell Hymes brought to the forefront of linguistic discussion in the sixties and early seventies (Hymes 1985) - in many ways it is anchored to a structuralist cultural anthropological perspective, despite its "cognitive" overtones: when teachers claim that today they are primarily interested in developing learners' communicative competence, they may have in mind Hymes's Chomskyan-like idea that communicative competence entails the possession of knowledge of a "cultural grammar" (roughly speaking: knowing what to say to whom, when, where, and how), which is realised in actual communicative events by means of the situational deployment of a partly-shared, partly-idiosyncratic repertoire of communicative styles involving a choice of differential formal-functional elements to serve certain communicative needs. As such, the concept of 'communicative competence' embraces a cognitive-pragmatic or socio-cognitive view of cultural knowledge which, significantly, leaves untouched the issue of how that knowledge "sits in the head" of the speaker, that is, how it is mentally represented, or recognized both subjectivly and intersubjectively. In this sense, communicative competence is basically a kind of strategically developed type of 
knowledge geared towards solving communicative problems. Ethnographic research has shown that communicative events and practices vary cross-culturally, as there exist quite marked differences in verbal and non-verbal practices regarding how communicative competence is acquired and put to use; so, in order to avoid problems of communication we need to know (explicitly or tacitly) what the content of communicative acts should (or should not) be; how messages are sent or responded to, and in what situations and under what circumstances. Deficits in communicative competence show most evidently whenever members from different cultures, possessing different "cognitive-pragmatic environments" and tendencies, meet and engage in talk. Learners, then, respond by developing partly universal, and partly specific cognitive strategies of acquisition, deployment, adaptation, etc.; these strategies are molded by a culture's set of communicative styles, which arise from that culture's conception of what people are like, and how they should relate to each other. Such conceptions, in turn, determine certain psycho-social orientations and attitudinal values towards language and communication, for instance: the fact that silence is valued by Japanese, and openness by North-Americans; or the fact hat the expectations by adult members of some societies concerning the capacity of young children to understand their intentions vary crossculturally (Clancy 1986).

It seems obvious, then, that the placing of EdL on a more solid ethnographic, cognitive-pragmatic footing, in contrast to the earlier simplistic emphasis on structuralist cultural anthropology, has been a step in the right direction. Drawing on this, the new socio-cognitive and psycho-social orientation of the concept of communicative competence is evident in some models and theories of second language acquisition. For instance, such an orientation has served as the theoretical motif for models and theories such as: accomodation, nativization, intergroup and intercultural communication theories (cfr. Ting-Toomey and Korzenny 1989); these theories are ultimately of a psycho-social nature, as the problems and notions discussed in them make clear: (perceived) psycho-social distance, nativization tendencies, attrition, in-group and outgroup loyalties, etc (Garret et al. 1989; Haslett 1989; Clément 1996). For example, the kinds of problems implicit under the term 'culture shock' involve the complex cognitiveemotional, psychological and psycho-social adjustment triggered by a cognitivelydissonant exposure to another culture, which for some people may imply a near trauma (Craig 1986). To paraphrase Ned Seelye (1984), breaking rules of grammar is a negative point, but breaking social rules is more serious, because it will create ill will toward the speaker if the cultural differences are not understood. Under a psycho-social perspective, helping learners overcome such emotional problems of adjustment, means helping learners become aware of the underlying causes of the conflict, which is seen as arising from people's tendency to notice more saliently what is familiar to them and to reject the unfamiliar, a tendency in which are involved complex mental and emotional processes. 
This view calls for an understanding of the cognitive mechanisms underlying such emotive experiences. But clearly, unless we know more about how emotion, cognition and action come together in actual communicative practices, little of actual relevance will be taught by teachers (cfr. Schumann 1993).

Nevertheless, it can still be argued that, despite the welcome psycho-social emphasis in EdL theories and models, and hence of a certain rapprochement of the social sciences to the mind sciences, as evinced in the socio-cognitive view of commmunicative competence, the close relationship between the social sciences component and the mind sciences component that we have witnessed in the last decades within EdL theory has not gone far enough. In fact, it may be argued that that relationship may require a further, more challenging move, namely their integration under a single unified account. Although this goal is still far off, it might be achieved if the compartmentalization of the three scientific domains serving as the main components of EdL: linguistics, psychology, and anthropology/sociology, were to be overcome in favour of a certain degree of interdisciplinariness, which would entail the search for systematic, not just accidental, integrations of the theoretical and implicational insights derived from each of these major components. And here we come to the following proposal: it can be argued that a step in this interdisciplinary direction is offered by the discipline called 'cognitive anthropolinguistics', whose ultimate goal is that of bridging the gap between the language (or communication sciences), the "mind" sciences and the social sciences. The discipline labelled 'cognitive anthropology' (D'Andrade 1995), together with the resurgence of the neowhorfian approach to language and thought (Lucy 1992), and, especially, the notion of 'cultural cognition', seem to us to be in a good position to help to lay the foundations of such an integration. We will argue here for an integration of cognitive anthropology as a major component in Stern's educational linguistics model. To a consideration of this paradigm, as well as of to some its implications, we turn next. In the final section we will offer a brief illustration of a cognitive-cultural application option, using Stern's idea of a 'socio-cultural guide' for a cross-cultural pedagogical grammar, involving the concept of 'ethnic stereotype'.

\section{Some Remarks on Cognitive Anthropology and Cultural Cognition}

\subsection{Cultural Cognition and Cultural Models in Language and Thought}

Theoretically speaking, the driving motivation behind the cognitive anthropology model consists in the attempt to reconcile several recent strands of cognitive psychology with certain pre- and post-structuralist approaches in cultural anthropology (Shore 
1990). The ultimate goal of the model is to explain the nature, acquisition and implementation of 'cultural knowledge'. The notion of social action as collectively meaningful human behaviour has always been essential to both symbolic and cultural anthropology. But these schools, which flourished in the sixties and early seventies, according to their critics, lacked a comprehensive understanding of the cognitive structures and processes underlying the representation of the declarative and procedural knowledge they imputed to cultures' members. For cognitive anthropologists, a people's culture is not just (as traditional accounts have it) a people's customs, artifacts, tradition, etc, but rather "what they must know in order to act as they do, make the things they make, and interpret their experience in the distinctive way they do" (Holland and Quinn 1987:4). Concerning the relationship of cognition to culture, in the cognitive anthropology paradigm, meaningful intersubjective behaviour (and this encompasses not just actions and activities, that is, mentally-caused behaviour, but also emotion and, of course, verbal behaviour) is understood as a creative activity whereby a meaningseeking subject encounters a culturally-conventionalised meaning-system world. The locus at which this encounter takes place consists of a system of "cultural schemas" which have both a subjective and inter-subjective psychological reality as well as a social reality; these schemas have a motivational and directive-orientational force but at the same time are a repository of knowledge and practices, serving to guide action and to help interpret it. As such, cultural schemas are the nexus linking specific minds to particular cultural symbols, situations and contexts. A cultural schema is not just a network of propositions, or an imagistic thought. It is an interconnected pattern of interpretive elements with an addressable memory, priming effects, and prototypical effects (D'Andrade 1989). The cultural cognition model envisages a conception of meaning that may be called 'constructivist' (cfr. Grace 1987), closely connected to 'nonobjectivist' (cfr. Lakoff 1987), and 'experiential-phenomenological' (cfr. Varela, Thompson, and Rosch 1992) accounts. From this vantage point, the cognitive anthropologist' s view of cultural knowledge is one which stresses the active role played by 'cognitive and action schemas' in guiding people's interpretive and communicative behaviour; such schemas help individuals creatively engage in symbolic praxis, while at the same time the symbolic praxis itself provides the essential input to the cultural schemas. It follows from this conception of cultural knowledge and cultural meanings that how people cognize their world (in terms of their image-schemas, cultural-schemas, conceptual metaphors, typical scenarios and frames, etc.) constrains and shapes how they-in-society frame experience, supply interpretations of that experience and inferences about it, and set goals for action (Holland and Quine 1987). Again, it follows from this that,

"cultures differ less in their basic cognitive skills than in the metaphors by which they live, the world hypotheses to which they subscribe, and the ideas 
underlying their social action ... Different people not only adopt distinct world views, but these world views have a decisive influence on cognitive thinking ... In particular, what one thinks about and how one thinks may be mediated by the world premises to which one is committed and by the metaphors by which one lives" (Shweder and Bourne 1984:198).

To sum up, cognitive anthropologists stress the fact that a culture has a conceptual structure, that languages are cultural constructions, and that understanding and using language entails activating the implicit cultural models and cultural assumptions underlying the terms and expresions. In the words of Casson (1994), "culture is the mental equipment that society members use in orienting, talking about, categorizing, and interpreting actual social behaviour in their society". Cultural knowledge is encoded in schemas representing the shared, intersubjetive conceptual knowledge. This knowledge is encoded in conceptual structures with representational, motivational and procedural power. The objects of representation may be entities, properties of these entities, events, sequences of stereotypical events, etc. Thus, lexical units, linguistic propositions, idiomatic structures, proverbs, pragmatic norms and rules, etc., may encode a lot of cultural information. A cultural model is, then, a conceptual structure made up of intersubjectively-shared "simplified" "schematic" version of events in the world. Some cultural models are scripts for actions (eg. going to a restaurant, rituals, games, etc.,), but others are more axiologically oriented and typically encode in a propositional-plusmotivational format all the information members of a culture possess that enables them to:

- represent schematically and prototypically knowledge about objective or imaginary reality;

- provide versions of the world;

- help interpret information;

- help synchronize, coordinate social cognition and meaning production;

- evoke connotations;

- entail belief-systems;

- cause affect;

- orient actions;

- entail motivational forces;

- regulate institutional behaviour;

In other words, they provide common conceptual, attitudinal, motivational and axiological orientations in mental models of language, affect, action and and thought through myths, belief systems, ideologies, world-views, etc. 


\subsection{Cultural Meaning and Intersubjectivity}

As argued above, cultural cognition is manifested in cultural models of language, thought, affect and action. The unifying concept here is that of intersubjective meaning', which in the current cognitive-linguistic paradigm corresponds to intersubjetive schematized declarative and procedural knowledge. Until the advent of this paradigm, in semantic theories, the emphasis has been on objectivist, logical, systemic, structural, and disembodied accounts of meaning. In that tradition, semanticists rarely talked about psychological meaning, let alone phenomenological, embodied, and motivational types of meaning. In particular, structural semanticists stressed the fact that most words are arbitrary, conventional signs and that their semantic import or value comes from their intensional relations to other signs in the language. And yet, despite their seeming structural conventional arbitrariness, anthropologists have drawn attention to the fact that signs have a way of acquiring transparency and motivation. This raises the problem of the relationship of the logical status of signs to their psychological status. Cultural anthropology and structural semantics lacked a model of the process of sign-formation. Purely structuralist theories lacked the resources to account for the natural motivation of signs and symbols, because they tended to avoid the problem of the epistemic status of subjective and intersubjective meaning. Intersubjective meaning is certainly an important construct in pragmatic theories of meaning as well as in relevance theory. In the former, intersubjective meaning is approached from a goal-oriented perspective, while in the latter it is a side-effect of the processing mechanisms in charge of meaning-interpretation. Cognitive anthropology, for its part, stresses the conceptual-representational, and affective-motivational aspects of intersubjective meaning: a language, amongst other things, serves as the repository of this knowledge, and through the symbolic projections of language we make public our thoughts and emotions and we can coordinate our social practices. This point is illustrated by M. Spiro as follows:

"Culture is public because it is encoded in collective representations or public signs. It is precisely for that reason that anyone can learn the culture of any social group. Since the meanings of those signs consist of the concepts they designate, cultural encodings are public because their meanings are located in the signs, ie the signs function simultaneously as both signified and signifier. When the signs are learned by social actors, they become personal, now being located in sombedy's mind. In this way, thoughts and emotions are culturally constituted. There are, thus, public collective representations of cultural symbols and private mentalemotional representations, as well as attitudes to them, the latter being conscious or unconscious" (1984: 323-4). 
Cognitive anthropology compels us, then, to move not only beyond the purely objectivist, logical, "disembodied" view of linguistic signs, which decouple mind, world and texts, but also beyond the purely subjectivist view implicit in many cognitive theories of meaning, which still reproduce a Cartesian, self-contained view of mind (cfr. McCulloch 1995). In this way, cognitive anthropology is akin to non-objetifying accounts of sign structure and processes, in which the embodied, intentional and motivational aspects of sign-formation and sign-experience are of paramount importance (Lakoff 1987). The implication is that the process of signification is both psychological and socio-cultural, and that a purely logical, system-based account of meaning, devoid of sensorial, embodied, psychological or social import, is narrow-minded. For instance, as is known, many words have an embodied and imagistic motivational origin, and others have not just a 'constituted' character (Searle 1995), based on a the intersubjective formula: 'X COUNT AS Y', (cfr. Fillmore's famous description of the frame for 'bachelor') but also a directive, motivational force, for they can guide our beliefs and thoughts, drive our actions, and influence our desires and emotions, in culturallyappropriate ways (D’Andrade 1989) Thus words have a way of supplying not just a subjective conceptual-representational function but also an intersubjective motivational, directive one. Because of this shared function, communication, understanding and interpretation of meaning is, most of the time, so effort-free. Clearly, then, a unified account of meaning would have to come to terms with the subjective and intersubjective aspects of representation and motivation, which tend to become overlooked not just by by purely structuralist but also by Cartesian views of meaning and mind, and which go a long way towards explaining many aspects of meaninginterpretation and meaning-construction processes. We create and use linguistic expressions and terms that reflect not only our natural (universal) conceptual capabilities but also our cultural conceptions. Take, for example the concept of person in our culture. Note the metaphoric structure of the following Spanish expressions (Martín Morillas, en prensa):

- ser un cara

- estar fuera de sí

- estar salido

- estar en una nube/las nubes

- estar por los suelos

- faltarle a uno un tornillo/chip

- estar atacado de los nervios

These expressions contain ways of speaking which "betray" the way Spanish speakers conceive of people, that is how verbal thought and conceptual thought interact cognitively- 
culturally. The above examples reveal an underlying naturally embodied as well as culturally conventionalized process of meaning-construction : they tell us something about the way we conceive of ourselves in our culture, and also something about the way the Spanish "cultural mind" draws on the resources of "embodied cognition" to create symbols from natural-cultural experience: "self as 'inner and outer' space, which can be invaded by external forces"; "self as 'orientational space"; "self's mental function as function of machine parts", etc. With our embodied conceptual apparatus we "construct" and "project" mental models and cultural images through language. On language we project our conceptual categories and in this way we create public signs and public meaning systems that everyone who knows the language can recognize. In other languages, similar, nearsimilar or outright different processes may occur (cfr. English: "to have a screw loose", "to be a cheek", etc). Again, consider one specific type of cultural practice: business. Here a number of cognitive schemas (reflecting certain conceptualizations, beliefs, assumptions), and action schemas (reflecting certain attitudes, motivations, normative courses of action, social scripts, and typical scenarios), are encapsulated in such phrases as: "what I do is my business"; "the business of business is business"; "business means war"; "business is a jungle"; "business is a game of winners and losers", etc. Cognitive-culturally, in our society business practices are schematically represented in a series of cultural models and conceptual metaphors: the jungle metaphor, the game metaphor, the war metaphor, etc. Some of these everyday phrases, conceptualizations and metaphors have in fact become further elaborated and appear encapsulated into higher-order cultural models (eg. the profit motive), or stereotypical concepts (eg. the self-made man), or standards of behaviour (individualistic work ethic), or action schemas or scripts (the competition model).

Semantically, then, cognitive anthropology goes along with the shift from formalist, feature-based theories of cognitive semantics to prototype-based, schema-based theories of knowledge representation, but emphasizing the interdependence of subjective and intersubjective processes and structures of meaning-construction and meaningunderstanding. At the same time, the implication is that an understanding of human cognitive systems cannot limit itself to the specification of structures and processes of knowledge representation, but must seek to embed this in the psycho-cultural processes underpinning axiological-orientation systems (beliefs, values, norms), and affective and directive forces (emotions, motivations, attitudes).

\subsection{Meaning and Cultural Learning}

The above view of meaning as a schema-driven activation of shared intersubjective conceptual and affective (explicit and implicit) types of knowledge underlying the process of understanding and comunication, entails a view of learning that seeks to 
overcome the limitations of the views implicit in purely innatistic, Cartesian-oriented, or radical empiricist models; and a view of communication beyond the idea of just information-transmission or interpretation of knowledge structures. In keeping with an experiential view of meaning-construction, learning is a creative activity of the mind upon the world that employs external experience to re-create previously incorporated forms of knowledge (by means of meaningful, not mechanical, accretion, tuning, and restructuring cognitive processes). These meaning-creative processes operate within the symbolic confines of a culture-bound world of meanings, which acts as both a repository and as an incentive for transcendence intra- and inter-communicatively, that is, communication involves the sharing of meaning-construction and meaninginterpretation processes in contexts where selves meet and share their cognitive environments following the norms and rules implicitly encoded in the communicative style and the psycho-social orientations of the culture of which they are competent members. How does this view apply to foreign and second language learning, the focus of interest for EdL? In foreign and second language learning, learning to communicate (developing an intercultural communicative competence) entails the learner's cognitivecultural re-organization of his/her cognitive-affective environments, as well as the cognitive-cultural re-organization of his communicative orientations-needs, both of which are, implicitly and transparently, part of his/her 'cultural-self'. The reorganization arises as a result of that 'cultural self' coming into contact with other 'cultural selves', whose cognitive environments and communicative orientations are partly different and partly similar to his/her own, thus causing the need for "pragmatic adaptation”, in the sense of Jeff Verschueren: “...adaptation is a [two-way] process: by choosing a 'mode of communication', speech gets consciously adapted to certain beliefs and goals ... but that adaptation itself entails various kinds of beliefs and goals which then further determine the course of interaction" (1987: 45).

\subsection{Language and Thought: The "Whorfian" Effect}

Another domain of communicative competence on which theories of cognition have traditionally had an important bearing is the language and cognition interface. Until recently, the Whorfian hypothesis had been dismissed outright. As Hunt and Agnoli remark, "the cognitive revolution in psychology virtually rejected [it], since, following Chomsky, the major trend in modern linguistics has been toward the study of universals [in language and thought], with a concomitant dismissal of the psychological importance of differences between languages" (1991: 372). But today a radical reassessment of this anti-Whorfian stance is under way, and with it the recognition that language can serve as a module-like vehicle, in the service of cognition. This is found to occur not only in the 
procedural aspects of language (for instance, in the differential influence of complex linguistic structures in processing time and effort), but also in the representational content of language (for instance, in the differential pre-packaging of prototypicalization effects of lexical metaphorization, or in the domain-activation in polysemous words in foreign language performance). Although in the cognitive-cultural model cognition and language are both seen as having a "cognitive-cultural" interface, it is now obvious that, despite their osmotic relationship, they are to be regarded as inter-dependent modules, each with its own representational and procedural mechanisms. That is, each can exert an influence on the other, in either direction. To a cognitive anthropolinguist, it is a fact that many properties of language are constrained by properties of human cognition; for example, there seems to be an upper bound to the number of taxonomic terms in a language (about 64), due to limits in memory capacity; again, the limits of polysemy seem to be shaped by the cognitive need for striking a balance between the consistency and generality of lexical words (D'Andrade 1989) But this mind-to-language influence must be complemented by the inverse influence, the one producing Whorfian effects. In a sense, the Whorfian problem is closely related to the classical one of interference. In cognitive-cultural terms, a possible account of the Whorfian problem may be given in terms of an "eco-cognitive model": first, the possession of a first language involves a kind of "imprinting" that creates a sort of "default" "cognitive-cultural environment" in the mind. When this native "imprinted, default system" attempts to incorporate, during second or foreign language learning, a "foreign system" (with its own "cognitivecultural environments") it tends to do so by accomodating it to its internal structural and processing functions and needs. Hence not only the possible negative transfer and interference tendencies, but also the Whorfian effects. Thus, understanding cultural cognition means not only understanding how people represent mentally, and deploy socially, their tacit socio-cultural knowledge; how they map this knowledge onto new types of knowledge embedded in new socio-cognitive environments; and how much of that knowledge involves activating common universal tendencies and how much involves specific, language-particular ones (Wierzbicka 1992), but also, how cognitive functioning is constrained by language knowledge and skills, and the other way around. Of course, it is very hard to know for certain to what extent a language is reflecting a world view or to what extent a language is shaping and controlling the thinking and the perception of its speakers by the requirements it makes of them. In fact, admitting the interdependence of language, cognition and culture does not by necessity commit one to a deterministic stance concerning their mutual influence, as J. Lucy makes clear,

"[The] problem for the relativity thesis is that influence of language on thought has been posited as having in mind a tertium comparationis: reality; here the only function of language studied has been the referential function; but other functions (expressive, social, esthetic) have not been investigated" (1992: 119). 
Let us now, by way of summary, list the most important goals that the cultural cognition model seeks to meet. Following Shore (1990), they can be summarized as follows:

1) accounting for the relation of 'subjective meaning' to 'intersubjective meaning'. We need a clear distinction between common worlds of meaning and overlapping individual worlds of meaning. This would enable the cognitive anthropologist to study the level at which meaning is shared within a group, class, population, etc, and the level at which individuals and groups are differentiated within a culture in terms of knowledge and experiential meaning. As Shore (1990) puts it, "we need a subject which can be both a WE and an I";

2) accounting for the relation between: a) logical (ie. system-based, or structuralist) notions of meaning and (b) psycho-somatic and phenomenological (embodied and imaginative) notions of meaning. The cognitive anthropologist should therefore seek to explain how the historically-opaque arbitrariness of signformation can be experienced subectively and intersubjectively as having a transparent, motivational significance and directive, agentive force. In this way, we would be able to link definitional accounts of meaning ("in this context, $\mathrm{X}$ means Y") to experiential accounts of subjective meaning ("for me/us, X means $\left.Y^{\prime \prime}\right)$;

3) accounting for aspects of meaning that go beyond the purely logical or conceptual, incorporating affective and sensorial aspects of meaning, and linking these to social micropractices;

4) accounting for the ontogenesis of meaning-construction, consistent with developmental psychology: early and adult symbol- and concept-formation processes;

5) accounting for the historical and local grounding of meaning-construction, hence its variability and relativity; however, the problem of relativism should not obscure the fact that meaning-systems may be commensurable and objective as well.

The following chart is intended to bring together the main elements of the general cognitive-cultural model (fig. 2): 


\title{
I. EMBODIED AND REPRESENTATIONAL CATEGORIES OF CULTURAL COGNITION
}

A. THE COGNITIVE SELF

(Representation of pre-conceptual and conceptual categories of:)

$\begin{array}{llll}\text { BODY } & \text { IMAGINATION } & \text { REASON } & \text { KNOWLEDGE } \\ \text { - Embodiment } & \text { - Conceptualization } & - \text { Reasoning } & \text { - Representation Schemas } \\ \text { Schemas: } & \text { Schemas: } & \text { Types: } & \text { \& Network of Concepts: } \\ \text { - spatial } & - \text { metaphoric mappings } & - \text { analogic } & \text { - episodic } \\ \text { - orientational } & - \text { metonymic mappings } & - \text { inferential } & \text { - verbal (declarative) } \\ \text { - kinesic } & - \text { blends } & - \text { propositional } & \text { - procedural (know how/action) } \\ \ldots & \ldots & \ldots & \ldots\end{array}$

\section{B. THE EMOTIVE SELF}

(Representation/Expression of Feelings) Body, Cognition, Emotion: Sensory Register Bodily Impression/Regulation \& Expression Cultural models and scripts

\section{THE PSYCHO-CULTURAL SELF} ("Cultural Personality")

-SELF AS oriented towards: Individualistic or Collectivistic in-group/ out-group tendencies, gender relations, loyalities, identities.. Thinking style, Social cognition style

- SELF AS contributor to:

Economic/Political/Legal Organization Power, Class, Status models Learning, Education models Institutionalization of Ideology: (actor, co-participant...)

\section{ENCAPSULATION AND ENACTMENT TENDENCIES OF CULTURAL COGNITION MODELS}

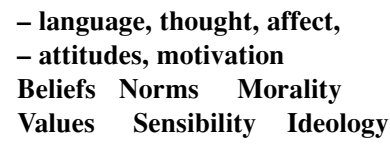

\section{ENCAPSULATION AND ENACTMENT OF MENTAL-CULTURAL MODELS IN: LANGUAGE AND SOCIAL ACTION}

\author{
-Discursive/Conversational/Textual - Social Scripts/Rituals \\ Verbal/Non-Verbal _ Games \\ Communication - Performative institutionalizations
}

Fig. 2. The main elements and categories of the Cognitive-Cultural Model 


\section{The Cognitive-Cultural Model as a Component of Educational LINGUISTICS}

As pointed out earlier, the cultural-cognitive perspective compels the educational linguist to look at how talk, thought, emotion and action come together in verbal behaviour, that is, in the relationship between thinking style, emotive style, and communicative style; or in how language expresions and categories encapsulate mental and cultural models. The overall picture of how the above general cognitive-cultural model could now be integrated with other disciplines making a contribution to EdL might look as follows (see fig. 3):

\section{A FRAMEWORK FOR THE INVESTIGATION OF CULTURAL COGNITION SYSTEMS}

\section{A. THEORETICAL FOUNDATIONS}

cognitive psychology

1. cognitive linguistics

cognitive anthropolinguistics R1 (“cultural cognition")

symbolic anthropology

2. ethnosemantics

micro- and macro-pragmatics

3. ethnography of communication

4. social cognition

cogitive socio-pragmatics

social psychology (“intercultural socio-cognition") $\quad$ R2

cultural psychology

B. IMPLICATIONS: interdisciplinary integration of concepts

C. APPLICATIONS:

- cross-cultural comparisons of ways of talking/thinking/feeling/doing

- culture teaching in EFL

- socio-cultural guides in communicative pedagogical grammars

- cultural studies

$-\ldots$

Fig. 3. The relationship of cultural and social cognition to EdL 
The difference between R1 and R2 in the model is intended to capture the difference between two types of meanings for the word 'Representation': a) Representation-1: as knowledge representation of intersubjective schemas underlying meaningful interaction; b) Representation-2: as pragmatic enactment of this knowledge in social practices of interaction (as such it encompasses the notion of 'communicative competence'). It must be emphasized that the relationship between 'representation-1' (explicit and implicit knowledge) and 'representation-2' (as competence underlying enactment) is dialectical: social action is based on intersubjective schemas (mental and cultural models, etc), while intersubjective schemas are in turn derived from social interaction practices (learning, communication, etc.).

In Stern's spirit, the model works by integrating information sterpwise in top-down fashion: the theoretical foundations supply the multidisciplinary concepts, notions and models that serve as the basis for drawing a number of implications depending on the nature of the applicational task.

To a brief discussion and illustration of the implication-application stages we turn next.

\section{The Problem of Implications and Applications}

As a prior step to the actual teaching and syllabus-design process, the communicative-competence-oriented educational linguist usually begins by investigating and developing a series of conceptual and thematic units intended to serve as a taxonomy of cross-cultural and cross-linguistic information to be used in communicative-competence-oriented projects. This is the level of Implications. Drawing upon this level, the educational linguist may next produce a number of Applications. One such type of implication-application is Stern's idea of 'socio-cultural guides for pedagogical grammars' (see Fig. 1 above). The possible thematic concepts and categories included in a socio-cultural guide project are manifold: typical social scripts, cultural models of self and emotions, cultural models of proverbs, psycho-cultural orientations in politeness, apology-making, etc. Here, I will focus my attention on socalled 'ethnic stereotypes' (cfr. Martín Morillas 1997) and sketch a possible line of implication-application.

\subsection{First Stage: The Theoretical Background: Towards Understanding the Concept}

Understanding the concept of ethnic stereotype entails a prior understanding of how cognitive-cultural concepts such as 'self', 'person', are categorized in the symbolic 
structure of languages, for the concept of ethnic stereotype is a derivative from the concept of 'self' and 'person'. Such a concept can be illustrated by statements such as "Andalusians are lazy", "Spanish men are passionate", or phrases such as "Latin lover", "Ugly American", French chauvinism", etc. These stereotypes are a mixture of singleself-categorization (the concept of 'person') and collective-self categorization (ie., what is usually called 'national image'). It is known that, from an anthropological perspective, the concept of self or person varies culturally (cfr. Shweder and Bourne 1984). In most cultures this concept is a composite of different kinds of traits and attributes: physical appearance, mental traits, behavioural tendencies, moral conduct, etc, as illustrated by the following descriptive and adscriptive propositional predications (Oerter et al. 1996):

1) self as "owner" of bodyparts and bodily functions: "X has a dark skin"

2) self as "owner" of psychological traits and mental competences: "X has a resourceful mind"

3) self as "owner" or "undergoer" of experiences and emotions: "X has a good heart" - "X is sensitive to criticism"

4) self as an actor in the social world: "X gets what $s /$ he wants"

5) self as an ethnic-identity carrier": " $X$ is a wetback".

6) self as a social-identity carrier: " $X$ is a yuppy"

7) self-as an affective-evaluative stimulus: " $X$ is a pain in the neck"

Cognitive-linguistic interpretations have been offered to account for the personcategorization process. According to 'vantage theory' (Hill and Mac Laury 1995), the diverse types of person categories attested in ethnographic works can be arranged in terms of a number of categorial dimensions, the most important of which are 'location' and "control' . The location coordinates are "intrinsic" (inside) vs. "extrinsic" (outside) (this conceptual categorization may derive from perceptual categories like self vs. other vs. environment). Between these there is a 'boundary' which separates other categories like: marks of identity, action tendencies, etc. The control coordinates, on the other hand, indicate the point or site at which the capacity for action is held to have its source or origin; again, a major perceptual dimension involved here is that of 'activity' vs 'passivity', and from this dimension there follow other categorizations pertaining to the types of forces or entities capable of exerting control, or causing things. Superimposed on these two dimensions there is a superordinate categorization based on attentional features: similarity vs difference. Interestingly, the latter superordinate categorization seems to serve a number of socio-cognitive functions which "pick up" other properties of the collective self: identity relations, communication, group loyalty, etc. For this purpose, the concept of person must include prototypical motivational, affective and action tendencies as well as prototypical social scripts and scenarios. 
Epistemically, person stereotypes are beliefs about the characteristic atributes, and behaviour of members of a certain group. A stereotypical concept is a category representing a series of attributes and features which are organized around a prototype, which constitutes the "default schematic version" of the group (Hilton and von Hippel 1996). The stereotype serves a number of functions: cognitive, social, affective, which in large part determine its formation and maintenance: the need to simplify the processing demands of the perceiver; the need to maintain the status quo, etc; the need to have a sense of superiority over others, etc. In terms of social cognition, a stereotype's categorization involves the possession and recognition of diagnostic, discriminatory features necessary for maintaining a sense of identity in social intercourse, which affects interpersonal or intercultural communication. This crystallizes in a certain 'attitudinal stance': opposition, acceptance, involvement, psychological and social distance, etc. When we talk stereotypically about other selves we betray our own cultural self constitution, that is, our talk is likely to betray the mental and cultural models that our culture has created as symbolic structures to refer to them. This does not mean that someone might not create his/her own mental models of self, but these idiosyncratic models are likely to lack intersubjective status. On the other hand, ethnic stereotypical concepts are a special class of 'collective-self stereotypical concepts'. As such they are constructed by integrating semantically various types of cognitive-cultural traits and properties that are schematically framed and encapsulated in the concept in question. The stereotype contains a conceptual and an evaluative content; the evaluative content tends to be either negative (cfr. Spanish 'sudaca', 'gringo'), or positive ('Latin lover', 'family-oriented', 'abierto/cálido'); as regards the conceptual content, in general, the most relevant parameters tend to refer to categories such as: race, gender, status, moral behaviour, physical appearance, mental competence, habits (eg. food consumption), and world-view (e.g. religious beliefs), to name but the most recurrent. Many cultural models are involved in self-stereotyping concepts, for instance, in gender stereotypes we typically find categories pertaining to sexual behaviour and physical and intellectual ability (cfr: "Women are weak", "French women are easy", "Men are superior"...). Other categories are: intimacy, friendship and affective relations ("Spanish people are warm, Scandinavians are cold"); work ethic and labour relations ("Andalusians are lazy”); power relations in politics (“Americans are imperialists”), prestige and status ("He is a go-getter"), etc. A "complex" definition of an ethnic stereotypical concept may well run together various types of mental and cultural models.

In cognitive-cultural terms, the main issue is the representational status of the above categories. The idea is that a stereotype has both an epistemic status and an affectiveattitudinal status, which, together, contain a certain behavioural disposition or directive force. The representation of these variables may be captured by a general schema containing the following attributes: 
1. Cognitive:

1.1. Beliefs

1.1.1. Attribution model

1.1.2. Predictive Expectations

2. Affective and Evaluative

2.1. Feelings

2.2. Attitudes

3. Enactment and Motivational Tendency

3.1. Verbalizing

3.2. Behavioural

This means that a stereotype category is a composite of conceptual, affective, attitudinal and predictive-expectational factors having an enactive motivationalbehavioural potential. Consider the Spanish word 'sudaca' mentioned above. Applying these factors to the Spanish word 'sudaca', we may have the following schema:

\section{'SUDACA'}

\section{Conceptual Content}

[origin: SouthAmerica] [social status: illegal emigrant] [activity: sells drugs]

$$
\begin{aligned}
& \begin{array}{l}
\text { <'marginado'> }>\text { 'camello'> } \\
\text { (social outcast) } \\
\text { <gets jobs needed by natives }>
\end{array} \\
& \text { <deserves extradition/ expulsion> }
\end{aligned}
$$

[attitude: rejection]

\section{Evaluative Content}

This schema can be recast in a propositional format as follows:

(a) Belief: X ISA Y

(i) Attribution model: BECAUSE causative mental model

(ii) Predictive: THAT'S WHY predictive mental model

(b) Affect : -EMOTIONAL VALENCY

(i) Evaluation: [negative]

(c) Enactive Tendency: [hostility/discrimination/stigmatization] 
The belief component is the result of stereotypical attribution and expectation models, for instance, the belief that emigrants "steal" the jobs that should go to native unemployed people; or the belief that they prefer to engage in illegal activities; or the prediction that they will threaten social order, etc. The evaluative content conveys the negative attitude of rejection, which, behaviourally, may surface as outright discriminatory practices, physical or symbolic violence, verbal stigmatization, or verbal abuse (for example, in racist expressions and racist discourse).

\subsection{The Second Stage: Drawing Implications-Applications}

In order to adapt the above general considerations about ethnic stereotyping behaviour to the problems of developing a socio-cultural guide as basis for comunicative-competence syllabus-design projects, the educational linguist must take into account a number of general and particular educational considerations. The problem for the educational linguist is twofold: first, to determine the degree of sharedness of the contents and values evoked by the stereotype: that is, to what extent the values are more or less intersubjectively constant, and not just merely subjectivist; secondly, to determine the "import" of the stereotype. Both are difficult problems. To sort out the first one, the educational linguist must rely on cross-cultural studies attempting to elucidate the scientific status of the concepts and values involved in the stereotype. Most serious, nonanecdotal studies of this kind make use of quantitative and qualitative techniques (for instance, multidimensional scaling, factor analysis) to arrive at principles ways of distinguishing the most relevant and reliable variables involved (cfr. Piedmont and Chae 1997)). The other problem is purely a value-oriented one. The educational linguist-cumteacher may feel that his or her students should develop a positive or a critical attitude towards the culture as part of the development of their communicative competence. This entails overcoming, criticizing, fostering, etc., certain conceptual and evaluative contents of the stereotypical images, ideas, beliefs, attitudes that they have towards members of the other culture. There seems to be little doubt that stereotypes produce Whorfian effects, as noted in the strong connotative content of many negative ethnic stereotypical categories, and their concomitant motivational and attitudinal influence in individual and social behaviour (D'Andrade and Straus 1992). For this purpose, the educational linguist may take it upon himself or herself, in language teaching, to tease apart the intimate relation between language, thought, emotion and action, in a way that may contribute, to the degree that it may be possible, to eliminating at least the most unfair, outrageous, or outright unacceptable cultural stereotypes existing either in the native or the foreign culture, as manifested in the language (ie. words, idioms, proverbs, phrases, types of discourse, etc). 
Research has shown that in learning a foreign language-culture, people are not entirely free of prejudice, unconscious images and stereotypes about it (Fiske 1993). They bring to the learning experience their beliefs, expectations, and attitudes about that culture. The native socialization process, the personal experiences, and many other factors may contribute to the formation of a subjective stereotype of the members of the foreign culture: what they are like, what they typically like to do, what they value most, how they reason, feel, etc. Thus, Americans are typically seen by Spaniards as individualistic, money-oriented, culturally naïve, enterprising, adventurous, optimistic, etc.; on the other hand, Japanese are seen as shy, gregarious, conformist, family-oriented, hard-working, etc.

The actual application stage will be glossed over here, but a few remarks will suffice. Drawing on the above implications, the educational linguist (or teacher) attempts to apply them to the actual teaching situation (in lesson-planning, lessonimplementation, work-projects, etc). One applied goal might be to develop the competence of being able to evaluate generalizations made by and about the members of the culture; one practical technique is the 'cultural assimilator' exercise (Seelye 1984). Cultural assimilators are a type of reading comprehension exercise which typically evokes some experience abroad by a learner or at home by a foreigner leading to the experience of cultural misunderstanding (cultural shock, bump or wrench; Kramsch 1993). The content may be cast in a conversational or textual format, which easily lends itself to role-playing activities, debates, discussions, reports, etc. Another technique may consist in revealing to the learner, as a kind of 'awareness-raising' exercise, the cognitive-cultural categories underlying the stereotypical concepts in question, later to be used in the actual syllabus-design project. For instance, in the preparation of a sociocultural guide of English-Spanish national stereotypes, the educational linguist may collect samples of data from native informants and apply to them some of the concepts used by cognitive linguists, cognitive anthropologists and cultural psychologists. As an illustration, consider the following brief descriptions offered by a Spanish-speaking native English informant:

- Typical Spanish person: “impetuoso, cálido, mal organizado, efervescente, ruidoso, le da igual la hora, todo lo deja para mañana, gesticula mucho cuando habla, Latin lover, la familia es muy importante.."

- Typical English person: “frío, lacónico, pragmático, obsesionado por la hora, poco expresivo, no mueve las manos al hablar, bien organizado, obsesionado por la seguridad, patriótico, tradicional, le gusta la familia real, guisa poco y come mal, no le importa hacer el ridículo.." We note the conventional conceptual metaphor 'people are objects with temperature' encapsulated in the word 'frío' for the cultural model of interpersonal affect relations; the metaphor 'people are containers of 
bubbling liquid' encapsulated in the word 'efervescente' for the cultural model of affective expressivity. Other models in the informant's text are based on the activation of culture-bound prototypical action models ("no mueve las manos al hablar"), or social scripts (“todo lo deja para mañana").

\section{Summary AND CONCLUSIONS}

Cognitive anthropology arose as a reaction against the prevailing Platonism of current cognitive psychology, as well as against some extreme forms of contextualism and relativism in current cultural anthropology. In contrast to a view which claims to be able to isolate a universal, internal, abstract, transcendent central processor and meaner (Dennett 1990) from external, concrete, local, environmental conditions, cognitive anthropologists claim that no sociocultural environment exists or has identity independent of the way human beings seize meanings and resources from it, while every human being has his/her subjectivity and mental life altered through the process of seizing meanings and resources from some socio-cultural environment and using them. Cognitive anthropology, therefore, addresses the fundamental question of the cultural constitution of human nature and in particular, the sociocultural constitution of human personality, thus emphasising themes such as 'intentionality', 'motivation', agentivity', 'symbolic interaction', 'symbolic mediation', 'constructivism', 'embodiment', etc. These themes are studied in relation to ethnic divergences in styles of thinking; conceptions of mind, self, emotion; ecology and social practices.

For cognitive anthropologists, therefore, language, thought and action go hand in hand. The output of concept-formation processes, namely: percepts, autonomous concepts, and metaphoric concepts, all arise through developmental ontogenetic processes triggered by socialization and enculturation forces. The cultural knowledge we end up having as a result of these processes gets embedded in a system of so-called folk and expert 'cultural metaphoric and metonymic models', whose main function consists in (D'Andrade 1989: 809):

- synchronizing and coordinating the creative aspects of language, cognition and social practice;

- supplying the possibility of sharing common orientations in terms of beliefsystems, scenarios, scripts, social dramas, myths;

- helping subjects re-utilise sensorimotor experience as a means of social symbolization through metaphoric signification patterns involving rituals, routines, institutional practices, artistic expression, rites of passage, etc. 
From this standpoint, then, language, cognition, emotion and action are to be kept interdependent and accounted for in an integrated fashion. To this end, we favour a merging of cognitive linguistic and cognitive anthropological ideas, concepts and models. The basic thrust of this integration is twofold:

a) that the way we talk is a projection of the way we cognize (ie. the way categorize things, objects, properties, events, etc.); and

b) that the way we cognize and talk is for the most part also contingent upon the way we live (ie the way we go about our daily individual and social lives, and the tasks the social milieu sets to our cognitive environment, ie. our cultural minds).

From our point of view, this discipline may offer fruitful insights into the relation of talk to thought and to action, by placing mind in the habitat of society and by placing society in the natural locus of the mind. The integration of the language sciences, the cognitive sciences and the social sciences would therefore receive support from the "seamless" nature of our talking, thinking and acting practices. This has direct bearing on our conception of the nature and scope of educational linguistics, conceived of as the integration of concepts of language, mind and society, for both theories of language teaching and teacher-training programmes.

\section{REFERENCES}

Casson, R.W. 1994. “Cognitive anthropology”. Handbook of Psychological Anthropology. Ed. P. K. Boch. Westport, CT: Greenwood Press.

Clément, R. "Social psychology and intergroup communication". Journal of Language and Social Psychology 15/3: 222-30.

Clancy, P. 1986. "The acquisition of communicative competence style in Japanese". Language and Socialization across Cultures. Eds. B. Schieffelin and E. Ochs. London: Longman. 213-251.

Craig, J.A. 1986. Culture Shock. Singapore: Times Book International.

D’Andrade, R. 1989. “Cultural Cognition”. Foundations of Cognitive Science. Ed. M. Posner. Cambridge, Mass: The MIT Press. 795-831.

D'Andrade, R. 1995. Developments in Cognitive Anthropology. New York: Cambridge University Press.

D’Andrade, R. and Strauss, C. 1992. (eds.). Human Motives and Cultural Models. Cambridge, Mass: Cambridge University Press.

Dennett, D. 1990. Consciousness Explained. New York: Simon and Schuster.

Fiske, S. 1993. "Social cognition and social perception". Annual Review of Psychology: 155-94. 
Garrett, P. et al. 1989. "The contexts of language learning: extending the intergroup model of second language acquisition". Language, Communication, and Culture: Current Directions. Eds. S. Ting Toomey and F. Korzenny. London: SAGE. 201222.

Grace,W. 1987. The Linguistic Construction of Reality. London: Croom Helm.

Haslett, B. 1989. "Communication and language acquisition within a cultural context". Language, Communication, and Culture: Current Directions. Eds. S. Ting Toomey and F. Korzenny. London: SAGE. 19-35

Hill, J., and Mac Laury, R.E. 1995. "The terror of Moctezuma: Aztec history, vantage theory, and the category of "person". Language and the Cognitive Construal of the World. Eds. J. R. Taylor and R. E. MacLaury. Berlin: Mouton/De Gruyter. 277331.

Hilton, J., and von Hippel, W. 1996. "Stereotypes". Annual Review of Psychology: 237-71. Holland, D. and Quinn, N. (eds.). 1987. Cultural Models in Language and Thought. New York: Cambridge University Press.

Hunt, E. and F. Agnoli. 1991. "The Whorfian hypothesis: a cognitive-psychological perspective". Psychological Review 98/3: 377-89.

Hymes, F. 1985. "Towards linguistic competence". AILA Review 2: 9-24.

Kramsch, C. 1993. Context and Culture in Language Teaching. Oxford: Oxford University Press.

Lakoff, G. 1987. Women, Fire and Dangerous Things. Chicago: Chicago University Press.

Lucy, J.A. 1992. Language Diversity and Thought. Cambridge, Mass: Cambridge University Press.

Martín Morillas, J.M. 1997. "La categorización estereotípica: un modelo cognitivocultural”. Estudios de Lingüística General (III). Eds. J.A. de Molina Redondo and J. de Dios Luque Durán. Granada: Método Ediciones.

Martín Morillas, J.M. “The concept of 'self': its categorization and expression in Spanish". Language Design (in press).

McCulloch, G. 1995. The Mind and its World. London: Routledge.

Oerter, R. et al. 1996. "The concept of human nature in East Asia: etic and emic characteristics". Culture and Psychology 2/1: 9-53.

Piedmont, R. and J.H. Chae. 1997. "Cross-cultural generalizability of the five-factor model of personality”. Journal of Cross-cultural Psychology 29/2: 131-55.

Searle, J. 1995. The Social Construction of Reality. New York: Basic Books.

Seelye. N. 1984. Teaching Culture: Strategies for Intercultural Communication. Lincolnwood, Ill. National Text Co.

Shore, B. 1990. "Twice-born, once-conceived: meaning-construction and cultural cognition”. American Anthropologist 93: 9-27. 
Shore, B. 1995. Culture in Mind: Cognition, Culture and the Problem of Meaning. Oxford: Oxford University Press.

Schumann, J. 1993. "Where is cognition?". Studies in Second Language Acquisition 16: 231-242.

Spiro, M. 1984. "Some reflections on cultural determinism and relativism with special reference to emotion and reason". Culture Theory: Essays on Mind, Self, and Emotion. Eds. R. Shweder and R.A. LeVine. Cambridge, Mass: Cambridge University Press. 323-347.

Shweder, R., and Bourne, E. J. 1984. "Does the concept of person vary crossculturally?". Culture Theory: Essays on Mind, Self, and Emotion. Eds. R. Shweder and R.A. LeVine. Cambridge, Mass: Cambridge University Press. 200-214.

Stern, H.H. 1983. Fundamental Concepts of Language Teaching. Oxford: Oxford University Press.

Varela, F., Thompson, J., and Rosch, E. 1992. The Embodied Mind: Human Cognition and Experience. Cambridge, Mass: The MIT Press.

Verschueren, J. 1987. Pragmatics as a Theory of Linguistic Adaptation. IPRA Working Document 1.

Wierzbicka, A. 1992. Culture and Cognition: Universal Human Concepts in CultureSpecific Configurations. Oxford: Oxford University Press. 